Cláudia Karina Ladeia Batista ${ }^{1}$ Mário Lúcio Garcez Calii ${ }^{1}$

\title{
O DIREITO FUNDAMENTAL DE ACESSO A MEDICAMENTOS E A FUNÇÃO SOCIAL DA PROPRIEDADE IMATERIAL NO BRASIL
}

The fundamental right of access to medicines and the social function of intangible property in Brazil

${ }^{1}$ Universidade Estadual de Mato Grosso do Sul. Campo Grande/MS, Brasil. Correspondência: Mário Lúcio Garcez Calil. E-mail: mario.cali|@yahoo.com.br.

Recebido em: 20/03/2015. Revisado em: 08/06/2015. Aprovado em: 10/06/2015. 


\section{RESUMO}

O objetivo do presente trabalho é estudar as relações entre o direito de acesso a medicamentos e o direito de exclusividade na exploração de inventos farmacêuticos, a partir do direito fundamental à saúde em suas várias dimensões. Este objetivo será buscado por intermédio de pesquisa bibliográfica e documental. O presente estudo é justificado tendo em vista que o acesso a medicamentos constitui, atualmente, parcela indispensável do direito fundamental à saúde, devendo ser equilibrado com o direito de patente, considerando-se que toda propriedade, inclusive a imaterial, tem uma função social. Conclui-se que é necessário harmonizar o direito à preservação da propriedade imaterial - e, consequentemente, à exclusividade na exploração econômica do produto desenvolvido e patenteado - com o direito de acesso aos medicamentos, sob pena de se esvaziarem ambas as garantias constitucionais.

\section{Palavras-Chave}

Direito de Acesso a Medicamentos; Direito de Patente; Preservação da Propriedade Imaterial.

\section{ABSTRACT}

This is a literature and documental research aiming at studying the relationship between the right of access to medicines and the right to exclusivity in the exploitation of pharmaceutical inventions, from the fundamental right to health in its various dimensions. This study is justified by the increasing importance that the access to medicines currently has in the fundamental right to health, and by the necessity of balancing this right with the patents, if seen that all property, including intangible, has a social function. We conclude that it is necessary to harmonize the right to preserve intangible property -and, as a consequence, to preserve the economic exclusive exploitation of a developed and patented product- with the right of access to medicines, at risk of losing both constitutional guarantees.

\section{Keywords}

Preservation of Intangible Property; Right of Access to Medicines; Right of Patent. 


\section{Introdução}

A fundamentalidade do direito à saúde é evidente no texto constitucional de 1988. O direito de propriedade imaterial também é expresso na referida Carta, contudo não alcançando o mesmo dimensionamento e, portanto, não sendo merecedor do mesmo nível de segurança e garantia.

Parcela fundamental da saúde na atual quadra da história repousa na utilização de fármacos medicinais como forma de prevenção e cura de doenças, assim como na necessidade de constante desenvolvimento de tais produtos. Não se pode imaginar, hoje, a saúde sem os medicamentos adequados ao tratamento de cada mal.

\section{Metodologia}

Tendo em vista que o objetivo do presente trabalho é estudar as relações entre o direito de acesso a medicamentos e o direito de exclusividade na exploração de inventos farmacêuticos, a partir do direito fundamental à saúde em suas várias dimensões, procedeu-se à pesquisa bibliográfica - na literatura jurídica pertinente - e documental - na legislação aplicável e na jurisprudência do Supremo Tribunal Federal.

$\mathrm{O}$ trabalho divide-se em três partes. A primeira trata do direito à saúde em suas diversas dimensões, inclusive o acesso a medicamentos. A segunda aborda a relação entre os direitos à saúde e à propriedade imaterial. A terceira refere-se à função social das patentes farmacêuticas e ao equilíbrio entre a propriedade intelectual e $\mathrm{o}$ acesso a medicamentos.

\section{Justificativa}

Justifica-se o presente estudo tendo em vista que o acesso a medicamentos constituiu, atualmente, parcela indispensável do direito fundamental à saúde, devendo ser equilibrado com o direito de patente, uma vez que toda propriedade, inclusive a imaterial, tem uma função social.

\section{Resultados}

Por intermédio da presente pesquisa, foi possível concluir que se faz necessário harmonizar o direito à preservação da propriedade imaterial - e, consequentemente, à exclusividade na exploração do produto desenvolvido e patenteado - com o direito fundamental de acesso aos medicamentos.

\section{IV. $\mathbf{O}$ direito fundamental à saúde}

O próprio conceito de "saúde" é de complexidade extrema, pois é composto por fatores pessoais, ambientais e até mesmo administrativos. Referida complexidade 
projeta-se para além das ciências médicas e das ciências humanas em geral, vindo cobrar do direito uma conceituação sólida e aplicável aos casos concretos.

Em sentido amplo, "saúde" é a condição harmoniosa de equilíbrio funcional, físico e psíquico do indivíduo integrado dinamicamente em seu ambiente natural e social, ou a busca constante por tal estado, de forma que qualquer conceituação parte da ideia de equilíbrio interno e ambiental do homem ${ }^{1}$.

Em um Estado democrático e social de direito, em que os poderes públicos têm a obrigação de garantir o bem-estar da população, a saúde, enquanto parcela essencial da dignidade humana e instrumento de preservação da própria vida, passou a contar como um direito humano.

Com as Constituições modernas incorporando cartas de direitos fundamentais no século XX, a vida e a dignidade humana passaram a emoldurar todo o quadro de prerrogativas e de garantias que o Estado deveria efetivar, tanto a partir de abstenções quanto por intermédio de intervenções estatais na economia e na sociedade.

Assim, faz-se evidente que os direitos fundamentais formam um sistema de proteção à dignidade da pessoa humana. Referida proteção deve ocorrer da forma mais ampla possível, de modo a abranger tanto uma dimensão negativa (de abstenção) quanto uma dimensão positiva (de ação).

O direito à saúde, especificamente, é um dos direitos mais relevantes e complexos de que se tem notícia. Sua definição, inclusive nos tratados internacionais de direitos humanos, ocorre da forma mais ampla possível, abrangendo desde o direito à assistência até o direito ao desenvolvimento ${ }^{2}$.

$\mathrm{O}$ direito à saúde tem duas dimensões: uma objetiva, que protege o titular contra violações estatais e particulares; e uma prestacional, que compreende a consecução de medidas que garantam o gozo desse direito, bem como a organização de instituições, serviços e ações sem os quais não seria possível a fruição de tal direito ${ }^{3}$.

Não é possível analisar o direito fundamental à saúde sem considerar ambas as suas dimensões, inclusive no que concerne aos casos concretos. Tendo em vista que se trata de um direito amplíssimo, suas dimensões (defensiva e prestacional) são complementares e interdependentes.

Desse modo, vulnerar o direito social à saúde é vulnerar o direito à vida e à liberdade, "[...] entendida como possibilidade de cura ou convivência com a doença,

${ }^{1}$ DALLARI, Sueli Gandolfi; NUNES JÚNIOR, Vidal Serrano. Direito sanitário. São Paulo: Verbatim, 2011. p. $10-13$. ${ }^{2}$ DALLARI, Sueli Gandolfi. Direito sanitário. Revista Direito e Democracia, Canoas, v. 3, n. 1, p. 9, 2002.

${ }^{3}$ FIGUEIREDO, Mariana Filchtiner. Direito fundamental à saúde: parâmetros para sua eficácia e efetividade. Porto Alegre: Livr. do Advogado, 2007. p. 87-88. 
de modo que permita, em alguma medida, o exercício da autodeterminação e da consecução de um projeto de vida"4.

Trata-se, portanto, de direito extremamente complexo, assim como o próprio conceito de "saúde". Ambas as suas dimensões compreendem uma imensa gama de direitos relacionados à vida e à dignidade em vários graus de proteção. Conforme Sueli Dallari:

Observado como direito individual, o direito à saúde privilegia a liberdade em sua mais ampla acepção. As pessoas devem ser livres para escolher o tipo de relação que terão com o meio ambiente, em que tipo de cidade pretendem viver, suas condições de trabalho e, quando doentes, o recurso médico-sanitário que procurarão, o tipo de tratamento a que se submeterão, etc. Note-se, porém, que, ainda sob a ótica individual, o direito à saúde implica a liberdade do profissional de saúde para determinar o tratamento. Ele deve, portanto, poder escolher entre todas as alternativas existentes aquela que, em seu entender, é a mais adequada. É óbvio, então, que a efetiva liberdade necessária ao direito à saúde enquanto direito subjetivo depende do grau de desenvolvimento do Estado. [...] As limitações aos comportamentos humanos são postas exatamente para que todos possam usufruir igualmente as vantagens da vida em sociedade. Assim, para preservar-se a saúde de todos é necessário que ninguém possa impedir a outrem de procurar seu bem-estar ou induzi-lo a adoecer. Essa é a razão das normas jurídicas que obrigam à vacinação, à notificação, ao tratamento, e mesmo ao isolamento de certas doenças, à destruição de alimentos deteriorados e, também, ao controle do meio ambiente, das condições de trabalho, da propaganda enganosa. A garantia de oferta de cuidados de saúde do mesmo nível a todos que deles necessitam também responde à exigência da igualdade. É claro que, enquanto direito coletivo, a saúde depende igualmente do estágio de desenvolvimento do Estado 5 .

A abstenção estatal preserva a dignidade; a intervenção governamental garante a vida. Assim, o direito à saúde depende da liberdade, do desenvolvimento, da proteção ao meio ambiente e de ações que possibilitem seu exercício. A Constituição afirma o dever de todos os entes estatais no cuidado com a saúde ${ }^{6}$.

${ }^{4}$ SALAZAR, Andrea Lazzarini; GROU, Karina Bozola. A defesa da saúde em juízo: teoria e prática. São Paulo: Ed. Verbatim, 2009. p. 18.

${ }^{5}$ DALLARI, Sueli Gandolfi. Controle judicial da política de assistência farmacêutica: direito, ciência e técnica. Physis: revista de saúde coletiva. Rio de Janeiro, n. 20 v. 1, p. 59-60, 2010. Disponível em: <http://www.scielo.br/pdf/ physis/v20n1/a05v20n1.pdf>. http://dx.doi.org/10.1590/S0103-73312010000100005.

${ }^{6}$ BRASIL. Constituição da República Federativa do Brasil de 1988, de 05 de outubro de 1988. Disponível em: <http:// www.planalto.gov.br/ccivil_03/constituicao/constituicaocompilado.htm>. Acesso em: 28 abr. 2016. 
Em Estados democráticos e sociais de direito, a exemplo do Brasil, os poderes públicos devem cumprir uma tarefa essencial: garantir o bem-estar do povo. A concretização de tal dever se demonstra completamente impossível sem a efetiva preservação da saúde da população do país.

O direito à saúde, portanto, deve ser implementado por intermédio dos serviços públicos sanitários, pela construção de hospitais e postos de atendimento à população, pela contratação de profissionais especializados e, em especial, pelo acesso a medicamentos voltados à prevenção e à cura de doenças.

As ações estatais, portanto, são indispensáveis para a realização total do direito humano fundamental à saúde. Não bastasse, é claro que não se poderia efetivar o direito à saúde de forma plena sem que fosse assegurado o direito de acesso aos medicamentos, insumos essenciais aos procedimentos médicos e ambulatoriais.

\section{Direito de acesso aos medicamentos como dimensão essencial do direito à saúde}

É impossível efetivar o direito à saúde de maneira completa sem garantir o acesso a medicamentos. A ambivalência do referido direito determina que sejam tomadas posturas e ações estatais voltadas a sua efetivação, de modo que o acesso à medicação, essencial à prevenção e à cura, é seu evidente corolário.

O abastecimento e a distribuição de medicamentos devem ser feitos de forma abrangente, articulada e organizada, buscando sempre o atendimento integral da população e observando, em especial, a diretriz de descentralização, constante do artigo 198, inciso I, da Constituição Federal ${ }^{7}$.

Não se trata apenas de uma questão jurídica. As ciências médicas, há séculos, têm o medicamento como ferramenta essencial à prevenção e à cura de doenças. A relação entre medicina e medicamentos resta, inclusive, cristalizada na comunidade, constituindo um anseio social. De acordo com Ramiro Nóbrega:

Saúde e medicamentos estão estreitamente ligados em nossa sociedade. É difícil pensar a saúde ou a doença sem pensar em medicamentos. Quando vamos ao médico, esperamos receber uma receita ao final da consulta. E desejamos comprar aquele remédio que acreditamos ser a solução para os nossos problemas. Mas antes de efetuar a compra, duas coisas são necessárias: o medicamento deve estar disponível e precisamos de dinheiro para comprá-lo. Os avanços tecnológicos permitiram o desenvolvimento de medicamentos para quase todos os males, principalmente para aqueles mais "rentáveis” para a indústria farmacêutica.

${ }^{7}$ MAPELLI JÚNIOR, Reynaldo; COIMBRA, Mário; MATOS, Yolanda Alves Pinto Serrano de. Direito sanitário. São Paulo: Imprensa Oficial, 2012. p. 99. 
Doenças antes mortais já possuem cura ou tratamento adequado. Câncer, AIDS, diabetes, impotência, disfunções hormonais, etc., não há mal para o qual não exista uma pílula que combata seus efeitos. Esse fantástico desenvolvimento traz muitas soluções, mas cria inúmeras necessidades. Encontrar o medicamento desejado é fácil, mas adquiri-lo tornou-se um problema ${ }^{8}$.

Os medicamentos, portanto, são essenciais à saúde atualmente. O desenvolvimento da tecnologia médica cria para o Estado o dever fundamental de adequação às novas técnicas, e sua consequente utilização voltada ao bem-estar da população, consistente na prevenção e na cura de doenças.

A evolução científica da medicina, ao identificar problemas de saúde e encontrar soluções, torna-se constantemente mais ampla. $\mathrm{O}$ direito, enquanto sistema dinâmico que é, não pode ficar imune a tal evolução, devendo caminhar lado a lado com o desenvolvimento medicinal ${ }^{9}$. De acordo com Fábio Konder Comparato:

Ora, uma das dimensões essenciais do princípio republicano é de que os bens, materiais ou imateriais, indispensáveis à vida humana em condições de dignidade não podem ser apropriados por particulares. Dentre esses bens, assim qualificados por princípio como comuns a todos, estão, como ninguém hoje contesta, a ciência e a tecnologia. Escusa lembrar que um dos índices mais significativos de atraso ou subdesenvolvimento dos povos reside, justamente, no baixo grau de difusão do conhecimento científico e tecnológico. Temos, portanto, que à falta de expressa ressalva no texto constitucional, a criação de um privilégio, ainda que temporário, do uso empresarial de uma inovação tecnológica violaria, frontalmente, o princípio republicano de que o conhecimento científico ou tecnológico deve fazer parte do domínio público ${ }^{10}$.

Além disso, a dimensão híbrida do direito à saúde determina a mesma complexidade no que se relaciona ao direito de acesso a medicamentos. Não é apenas um direito social, voltado à ação estatal; tem, também, uma dimensão libertária, defensiva. De acordo com Sueli Dallari, o direito à assistência farmacêutica é uma das dimensões do direito à saúde:

\footnotetext{
${ }^{8}$ NOBREGA, Ramiro. Acesso a medicamentos: direito garantido no Brasil? In: COSTA, Alexandre Bernardino; SOUSA JÚNIOR, José Geraldo de; DELDUQUE, Maria Célia; OLIVEIRA, Mariana Siqueira de Carvalho; DALLARI, Sueli Gandolfi (Orgs.). O direito achado na rua: introdução crítica ao direito à saúde. Brasília: CEAD/UnB, 2009. p. 307.

${ }^{9}$ MAPELLI JÚNIOR, Reynaldo; COIMBRA, Mário; MATOS, Yolanda Alves Pinto Serrano de. op. cit., p. 18.

${ }^{10}$ COMPARATO, Fábio Konder. O abuso nas patentes de medicamentos. Revista de Direito Sanitário, v. 11, n. 3, p. 211, fev. 2011. Disponível em: <http://www.revistas.usp.br/rdisan/article/view/13229/15044>. http://dx.doi.org/10.11606/issn.2316-9044.v11i3p204-219.
} 
O direito ao medicamento compartilha dessas características, não sendo parte exclusivamente do que se convencionou chamar de direito social e nem somente do direito civil. De fato, o medicamento é um objeto híbrido, ao mesmo tempo mercadoria e bem sanitário, fazendo com que o direito que dele se ocupa tenha aspectos puramente contratuais clássicos, decorrentes de sua faceta mercadológica, outros claramente associados aos direitos sociais, que implicam a disciplina legal do acesso a eles enquanto bens indispensáveis ao cuidado da saúde, e outros ainda que estão na estrita dependência do desenvolvimento econômico-social e cultural e que vêm sendo denominados por seu caráter transindividual, identificáveis na proteção aos conhecimentos tradicionais ou na avaliação dos riscos e benefícios éticos dos ensaios clínicos, por exemplo ${ }^{11}$.

O direito de acesso a medicamentos, dessa forma, compartilha a natureza do próprio direito à saúde. Ao mesmo tempo em que se deve preservar a liberdade de comércio das empresas produtoras e distribuidoras de fármacos, não se deve perder de vista a dimensão social que têm tais produtos.

Enquanto serviço público essencial, é evidente que as ações voltadas à saúde devem encontrar regulação estatal. Em relação ao fornecimento de medicamentos, não pode ser diferente. Tanto que existem, na legislação, diversos instrumentos regulamentadores em relação a tal esfera jurídica.

Nesse diapasão, foi instituída pela Portaria MS n. 3.916/1998 ${ }^{12}$ a Política Nacional de Medicamentos, que fixou a Relação Nacional de Medicamentos Essenciais (Rename). A lista “[...] serve como norte para a elaboração de listas de medicamentos pelos entes federados" ${ }^{\prime 3}$. No entanto:

[...] é importante esclarecer que a lista de medicamentos essenciais é instrumento para viabilizar garantias mínimas à população e não pode servir para limitar o acesso integral do indivíduo aos tratamentos que se mostrem necessários à manutenção de sua saúde. Até porque, a lista de medicamentos essenciais contém os medicamentos básicos, para as patologias mais comuns, de modo que terapias relevantes para o tratamento de alguns quadros de saúde podem estar excluídas de seu rol. O fundamental, tanto para pedido administrativo quanto para eventual ação judicial, é haver evidência científica da necessidade do produto fármaco ou do insumo terapêutico ${ }^{14}$.

\footnotetext{
${ }^{11}$ DALLARI, Sueli Gandolfi. Controle judicial da política de assistência farmacêutica: direito, ciência e técnica, cit., p. 63-65.

${ }^{12}$ MINISTÉRIO DA SAÚDE. Portaria n. 3.916, de 30 de outubro de 1998. Disponível em: <http://bvsms.saude. gov.br/bvs/saudelegis/gm/1998/prt3916_30_10_1998.html>. Acesso em: 28 abr. 2016.

${ }^{13}$ MAPELLI JÚNIOR, Reynaldo; COIMBRA, Mário; MATOS, Yolanda Alves Pinto Serrano de. op. cit., p. 107.

${ }^{14}$ Id. Ibid.
} 
Como se denota, mesmo a Rename, listagem fixada oficialmente pelo Ministério da Saúde, não se sobrepõe ao direito à saúde. Dessa forma, no caso concreto de haver enfermidade mais grave ou complexa, deve ser, em qualquer caso, assegurado $o$ acesso ao medicamento adequado.

Tendo em conta sua relação direta com o direito à vida e à dignidade humana, é possível afirmar a obrigatoriedade de o Estado assegurar até mesmo o acesso a medicamentos que não constam da Rename, de fármacos ainda não registrados pela Agência Nacional de Vigilância Sanitária (Anvisa) ou até mesmo de fórmulas experimentais.

Apesar de não encerrar todo o conteúdo do direito à saúde, o direito de acesso a medicamentos é uma de suas facetas essenciais, por questões tanto sociais quanto jurídicas, de modo que deve ser garantido plenamente pelo Estado. Nesse sentido decidiu o Supremo Tribunal Federal:

PACIENTE COM HIV/AIDS - PESSOA DESTITUÍDA DE RECURSOS FINANCEIROS - DIREITO À VIDA E À SAÚDE - FORNECIMENTO GRATUITO DE MEDICAMENTOS - DEVER CONSTITUCIONAL DO PODER PÚBLICO (CF, ARTS. 5', CAPUT, E 196) - PRECEDENTES (STF) - RECURSO DE AGRAVO IMPROVIDO. O DIREITO À SAÚDE REPRESENTA CONSEQUÊNCIA CONSTITUCIONAL INDISSOCIÁVEL DO DIREITO À VIDA. - O direito público subjetivo à saúde representa prerrogativa jurídica indisponível assegurada à generalidade das pessoas pela própria Constituição da República (art. 196). Traduz bem jurídico constitucionalmente tutelado, por cuja integridade deve velar, de maneira responsável, o Poder Público, a quem incumbe formular - e implementar - políticas sociais e econômicas idôneas que visem a garantir, aos cidadãos, inclusive àqueles portadores do vírus HIV, o acesso universal e igualitário à assistência farmacêutica e médico-hospitalar. - O direito à saúde - além de qualificar-se como direito fundamental que assiste a todas as pessoas - representa consequência constitucional indissociável do direito à vida. O Poder Público, qualquer que seja a esfera institucional de sua atuação no plano da organização federativa brasileira, não pode mostrar-se indiferente ao problema da saúde da população, sob pena de incidir, ainda que por censurável omissão, em grave comportamento inconstitucional. A INTERPRETAÇÃO DA NORMA PROGRAMÁTICA NÃO PODE TRANSFORMÁ-LA EM PROMESSA CONSTITUCIONAL INCONSEQUENTE. - O caráter programático da regra inscrita no art. 196 da Carta Política - que tem por destinatários todos os entes políticos que compõem, no plano institucional, a organização federativa do Estado brasileiro - não pode converter-se em promessa constitucional inconsequente, sob pena de o Poder Público, fraudando justas expectativas nele depositadas pela coletividade, substituir, de maneira ilegítima, o cumprimento de seu impostergável dever, 
por um gesto irresponsável de infidelidade governamental ao que determina a própria Lei Fundamental do Estado. DISTRIBUIÇÃO GRATUITA DE MEDICAMENTOS A PESSOAS CARENTES. $\mathrm{O}$ reconhecimento judicial da validade jurídica de programas de distribuição gratuita de medicamentos a pessoas carentes, inclusive àquelas portadoras do vírus HIV/AIDS, dá efetividade a preceitos fundamentais da Constituição da República (arts. 5º, caput, e 196) e representa, na concreção do seu alcance, um gesto reverente e solidário de apreço à vida e à saúde das pessoas, especialmente daquelas que nada têm e nada possuem, a não ser a consciência de sua própria humanidade e de sua essencial dignidade. Precedentes do STF ${ }^{15}$.

Como se demonstra, a Corte Suprema, ao interpretar a Constituição de 1988, posicionou-se no sentido da "fundamentalidade" do direito de acesso a medicamentos, inclusive enquanto direito social que o Estado deve garantir, especialmente no que concerne às pessoas carentes.

Ocorre que o direito de acesso a medicamentos deve restar equilibrado com o direito de propriedade imaterial referente às patentes de medicamentos. Como se demonstrará, não se pode pensar o desenvolvimento de novos medicamentos sem o respeito ao monopólio de utilização que o registro de patentes proporciona.

Não é possível, contudo, perder de vista o direito fundamental à saúde e o direito de acesso aos medicamentos, a serem efetivados pelo Estado. É necessário, assim, que tais direitos restem compatibilizados de maneira razoável, de forma a que se possam concretizar ambos.

\section{A função social da propriedade intelectual e a função social das patentes de medicamentos}

O direito de propriedade faz parte da própria história da humanidade, tendo sido essencial para a formação do próprio conceito de "economia". A evolução, porém, determinou o reconhecimento de direitos de propriedade para além dos bens corpóreos, palpáveis, diretamente resultantes do desenvolvimento humano.

A propriedade intelectual, portanto, é um produto do pensamento e da inteligência humanos, "[...] que também tornou-se, com o passar dos tempos, objeto da propriedade industrial. A propriedade intelectual é o esforço dispendido pelo ser humano, voltado à realização de obras literárias, artísticas e científicas, como também é o direito autoral"16.

\footnotetext{
${ }^{15}$ BRASIL. Supremo Tribunal Federal. RE 271.286-RS. Rel. Min. Celso de Mello. 2000. Disponível em: <www. stf.jus.br>. Acesso em: 31 maio 2012. n.p.

${ }^{16}$ MUJALLI, Walter Brasil. A propriedade industrial: nova Lei de Patentes. Leme: Ed. de Direito, 1997. p. 238.
} 
Com o passar das décadas, a propriedade intelectual tornou-se fundamental para a economia ao redor do mundo, decorrente, em grande parte, da necessidade de compensação por custos de pesquisas voltadas ao desenvolvimento de novos bens de consumo que, de úteis, passaram à essencialidade.

Nesse diapasão, a preservação do pesquisador no que se relaciona à concorrência é essencial para que a busca por novos produtos se mantenha financeiramente interessante. Tal característica tem especial relevância no que concerne às pesquisas que envolvem fármacos medicinais.

Ao se conferir proteção, pelos direitos de propriedade intelectual, ao desenvolvedor da inovação, atribui-se a ele a capacidade de reaver o investimento feito no desenvolvimento do novo produto ou processo produtivo. O resultado econômico de um custoso projeto de pesquisa e desenvolvimento, muitas vezes, não é previsível, sendo incerto o seu sucesso financeiro. Em vista disso, ao se conferirem direitos exclusivos de propriedade ao criador da ideia sobre o modo como a expressa faz com que possa se apropriar do valor social gerado, o que talvez não ocorresse se outros indivíduos pudessem usar, fruir e dispor da inovação sem ter contribuído para o seu desenvolvimento. Além disso, importa notar que, se na evolução biológica os mais aptos sobrevivem, na evolução econômica os mais aptos são emulados. Vale dizer, os mais aptos no mercado de inovações (os inovadores) atraem os concorrentes. Se estes tiverem o poder de se apropriar dos resultados da inovação dos mais aptos, imprimirão deslealmente a concorrência, vez que se beneficiarão dos frutos decorrentes sem terem incorrido nos custos inerentes ${ }^{17}$.

A Constituição de 1988 não se manteve inerte no que concerne a tal fato histórico-social. Tratou, portanto, de preservar o direito de propriedade intelectual. Ocorre que tal preservação não se deu pelo mesmo formato de garantia fundamental conferido à propriedade material.

O direito de propriedade referido pelo caput do artigo $5^{\circ}$ é um dos direitos fundamentais do homem. "Mas a disposição contida no inciso XXIX tem antes o aspecto de comando constitucional dirigido ao legislador ordinário - reprise-se: 'a lei assegurará...' - e não propriamente um reconhecimento automático de um direito fundamental do autor intelectual"18.

\footnotetext{
${ }^{17}$ TIMM, Luciano Benetti; BRENDLER, Gustavo. Análise econômica da propriedade intelectual: Commons vs. Anticommons. In: CONGRESSO NACIONAL DO CONPEDI, 18., nov. 2009. p. 1027. Anais... Disponível em: $<$ www.conpedi.org.br>. Acesso em: 20 mar. 2015.

${ }^{18}$ FURTADO, Lucas Rocha. Sistema de propriedade industrial no direito brasileiro. Brasília: Brasília Jurídica, 1996. p. 83.
} 
A natureza "não fundamental" do direito à propriedade imaterial demonstra claramente a possibilidade de relativização de tal direito. Ainda mais quando se está diante do conflito entre o referido direito e uma garantia fundamental. Esse conflito pode se dar, não raro, em relação ao direito à saúde.

Como se afirmou acima, o direito ao acesso a medicamentos deve ser assegurado por todos os poderes públicos. Referido direito deve, evidentemente, restar equilibrado com a garantia da propriedade imaterial referente aos medicamentos que são objeto de patentes registradas.

Inicialmente, o acesso a medicamentos somente pode ser garantido se houver quantidade suficiente de medicamentos a custos razoáveis. Mesmo se houver tal reserva, novos medicamentos são sempre caros demais para pessoas pobres, especialmente em países em desenvolvimento ${ }^{19}$.

A cadeia de suprimentos refere-se a todos os envolvidos na questão da distribuição de medicamentos, desde a saída da fábrica até o momento da venda e compra, com uma série infindável de oportunidades para o aumento de preços de tais produto ${ }^{20}$, inclusive de forma arbitrária.

A iniciativa privada, evidentemente, está voltada à obtenção de capital em troca de bens ou serviços. É de sua natureza buscar otimização dos lucros por intermédio da diminuição dos custos de produção e de fornecimento dos referidos bens, bem como tentar proteger-se da concorrência.

No caso específico dos fármacos medicinais, apesar da necessidade de obtenção de dividendos, os profissionais do ramo deveriam ter em mente que seu trabalho envolve indubitavelmente a preservação da vida humana, desde a pesquisa que resultou em sua criação até a distribuição do produto final.

A questão econômica, contudo, leva as empresas cujo objeto é o estudo, a fabricação e a distribuição de medicamentos a se concentrarem na busca por lucros gigantescos, deixando de lado a prevenção e a cura de doenças, e negligenciando, em especial, as necessidades das pessoas carentes.

Moldado pela demanda efetiva dos países industrializados, o mercado de medicamentos mostra-se inadaptado às necessidades de saúde das nações em desenvolvimento, trazendo assim o problema das doenças negligenciadas. Neste setor da inovação farmacêutica, as empresas são naturalmente conduzidas a concentrar seus interesses nos males que atingem, principalmente, os mercados mais rentáveis. Dessa maneira, as forças do mercado condicionam o setor de pesquisa e desenvolvimento farmacêutico

\footnotetext{
${ }^{19}$ HASSIM, Adila; HEYWOOD, Mark; BERGER, Jonathan. Health \& democracy: a guide to human rights, health law and policy in post-apartheid South Africa. South Africa: Siber Ink, 2007. p. 438.

${ }^{20}$ Id. Ibid., p. 441.
} 
mundial. Enquanto determinadas classes terapêuticas contam com uma intensa concentração de recursos financeiros, outras são excluídas dos programas de pesquisa. Resultado: para as doenças "negligenciadas", como o mal de Chagas, a dengue, a leishmaniose ou a lepra, não existem medicamentos ou as drogas são antigas e pouco eficazes. Neste contexto, qual o papel da patente farmacêutica na questão "mercado/doenças negligenciadas"? A resposta: nenhum. A equação entre o interesse da patente e a existência de um mercado lucrativo explica, em grande parte, a inutilidade dos direitos de propriedade intelectual quando se destinam a estimular o setor privado de pesquisa farmacêutica a tratar de atividades em benefício dos doentes de mercados mais ou menos restritos e, mais importante, pouco rentáveis ${ }^{21}$.

Dessa forma, uma parte extremamente relevante do direito de acesso a medicamentos esbarra em questões econômicas, especialmente no que concerne à propriedade intelectual, ou seja, ao direito de exploração dos medicamentos criados a partir de pesquisas custosas e complexas.

A preservação da propriedade imaterial, contudo, não se pode sobrepor ao direito fundamental à saúde; deve com ele ser compatibilizada, equilibrada, de modo a preservar ambos os direitos: o da empresa e o do cidadão que depende do medicamento para prevenir e curar doenças.

A proteção à propriedade intelectual não pode inviabilizar nem comprometer o dever do Estado de garantir o respeito, a proteção e a implementação do direito ao acesso a medicamentos, pois a propriedade intelectual é um produto social que possui uma indubitável função social ${ }^{22}$.

No Estado Democrático de Direito, a propriedade tem um regime diverso daquele que havia no Estado liberal. Aqui, a propriedade não deve ser sinônimo de riqueza individual; deve, sim, cumprir uma função social, de distribuição e circulação da riqueza, exigência que alcança a propriedade imaterial.

A propriedade industrial se insere no contexto jurídico por sua função social, que é a de possibilitar o avanço no conhecimento (estado da arte) como condição de sua proteção jurídica. Fala-se, evidentemente, do direito de propriedade industrial e não da propriedade industrial como um estado concreto de coisas.

\footnotetext{
${ }^{21}$ BRÉGER, Thomas. Economia internacional do saber e da pobreza: a exclusão dos países em desenvolvimento do mercado mundial de medicamentos. Revista de Direito Sanitário, São Paulo v. 12, n. 1, p. 145, mar./jun, 2011. Disponível em: <http://www.revistas.usp.br/rdisan/article/view/13241/15056>. http:// dx.doi.org/10.11606/issn.2316-9044.v12i1p135-188.

${ }^{22}$ BARRETO, Ana Cristina Costa. Direito à saúde e patentes farmacêuticas: o acesso a medicamentos como preocupação global para o desenvolvimento. Aurora, ano 5, n. 7, p. 9, jan. 2011. Disponível em: <http:// www.marilia.unesp.br/Home/RevistasEletronicas/Aurora/1barreto1a11.pdf >.
} 
Se fôssemos falar da circunstância concreta de apropriação (pela descoberta) de uma criação e de sua defesa (pelo segredo) contra a apropriação pelos demais membros da sociedade, não estaríamos falando da propriedade industrial no sentido mais usual de proteção estatal do domínio exclusivo dos frutos daquela criação. Estaríamos, pelo contrário, nos referindo ao segredo industrial, que é um método utilizado quando o particular não vê vantagens em divulgar para a sociedade o caminho que percorreu para desenvolvimento do produto ou processo inovador ${ }^{23}$.

A concessão do privilégio de exploração temporária do invento assegura ao autor o interesse no desenvolvimento da pesquisa, vez que terá ele um meio eficaz de recuperar os recursos investidos. Assim, um eficaz sistema de análise para a concessão de patentes acaba por representar importantíssimo fomento à atividade inventiva.

O desenvolvimento de novas tecnologias constitui, por sua vez, meio de efetivação de direitos sociais, notadamente na área de saúde. A proteção e o incentivo à atividade inventiva estão diretamente relacionados com o estabelecimento do direito de exploração exclusiva da inovação durante um lapso temporal.

De todas as estratégias até hoje experimentadas, nenhuma tem se mostrado mais eficiente na promoção da pesquisa e no desenvolvimento do progresso técnico, econômico e social do que o sistema de patentes. É a melhor forma até hoje conhecida para estimular o progresso industrial. Os países que melhor asseguram esse direito exclusivo aos seus inventores são os que mais conseguiram desenvolver-se. Os que hesitaram em fazê-lo, ficaram marcando passo ou muito lentamente progrediram, para não dizer que perderam suas melhores inteligências em favor dos primeiros. Até hoje tem sido uma constante: o progresso está na razão direta do grau de exclusividade conferida aos inventores ${ }^{24}$,

A proteção da patente fomenta a inovação, resultando indiscutível o efeito de que a grande maioria dos medicamentos verdadeiramente novos e valiosos é a criação da indústria farmacêutica privada e se deve a seus esforços próprios de investigação ${ }^{25}$. Assim, o problema de uma proteção eficaz das criações desempenha um papel decisivo.

\footnotetext{
${ }^{23}$ ARANHA, Márcio lorio. Propriedade intelectual e patente farmacêutica. In: COSTA, Alexandre Bernardino; SOUSA JUNIOR, José Geraldo de; DELDUQUE, Maria Célia; OLIVEIRA, Mariana Siqueira de Carvalho; DALLARI, Sueli Gandolfi (Orgs.). Introdução crítica ao direito à saúde. Brasília: CEAD/UnB, 2009. p. 403.

${ }^{24}$ HAMMES, Bruno Jorge. O direito de propriedade intelectual. São Leopoldo: Ed. Unisinos, 2002. p. 285.

${ }^{25}$ SOARES, José Carlos Tinoco. Tratado da propriedade industrial: patentes e seus sucedâneos. São Paulo: Ed. Jurídica Brasileira, 1998. p. 519.
} 


\section{Conclusão}

O direito à saúde é extremamente relevante e, além disso, de evidente complexidade, inclusive no que tange a sua definição e abrangência. Tem dimensão dúplice, ambivalente, constituindo tanto um direito fundamental de índole social quanto um direito libertário, de natureza defensiva, buscando preservar a dignidade em diversos graus.

Nesse sentido, ações estatais são indispensáveis para que se possa realizar tal direito de forma plena. Dentre tais ações, o acesso a medicamentos se revela indispensável, pois, é claro, não se poderia efetivar o direito à saúde sem os insumos essenciais aos procedimentos médicos e ambulatoriais.

O direito ao acesso a medicamentos, dessa forma, compartilha a natureza do próprio direito à saúde, restando necessário preservar a liberdade de comércio das empresas produtoras e distribuidoras de fármacos, porém sem perder de vista a dimensão social inerente a tais produtos.

É evidente que o desenvolvimento de novas tecnologias é um meio de efetivação de direitos sociais, de modo que a proteção à atividade inventiva está diretamente relacionada à exclusividade na exploração da inovação. Porém, ter esse direito como absoluto equivale a esvaziar uma indispensável dimensão do direito à saúde.

Assim, é necessário harmonizar o direito à preservação da propriedade imaterial - e, via de consequência, de exclusividade na exploração econômica do produto desenvolvido e patenteado - com o direito de acesso aos medicamentos, sob pena de se esvaziarem ambas as garantias constitucionais.

\section{Referências}

ARANHA, Márcio Iorio. Propriedade intelectual e patente farmacêutica. In: COSTA, Alexandre Bernardino; SOUSA JUNIOR, José Geraldo de; DELDUQUE, Maria Célia; OLIVEIRA, Mariana Siqueira de Carvalho; DALLARI, Sueli Gandolfi (Orgs.). Introdução crítica ao direito à saúde. Brasília: CEAD/UnB, 2009. p. 397-410.

BARRETO, Ana Cristina Costa. Direito à saúde e patentes farmacêuticas: o acesso a medicamentos como preocupação global para o desenvolvimento. Aurora, ano 5, n. 7, p. 1-11, jan. 2011. Disponível em: <http://www.marilia.unesp.br/Home/RevistasEletronicas/ Aurora/1barreto1a11.pdf $>$.

BRÉGER, Thomas. Economia internacional do saber e da pobreza: a exclusão dos países em desenvolvimento do mercado mundial de medicamentos. Revista de Direito Sanitário, São Paulo v. 12, n. 1, p. 135-188, mar./jun, 2011. Disponível em: <http://www.revistas.usp.br/ rdisan/article/view/13241/15056>. http://dx.doi.org/10.11606/issn.2316-9044.v12i1p135-188.

CAMPARATO, Fábio Konder. O abuso nas patentes de medicamentos. Revista de Direito Sanitário, v. 11, n. 3, p. 204-219, fev. 2011. Disponível em: <http://www.revistas.usp.br/ rdisan/article/view/13229/15044>. http://dx.doi.org/10.11606/issn.2316-9044.v11i3p204-219. 
DALLARI, Sueli Gandolfi. Controle judicial da política de assistência farmacêutica: direito, ciência e técnica. Physis: revista de saúde coletiva. Rio de Janeiro, n. 20 v. 1, p. 57-75, 2010. Disponível em: <http://www.scielo.br/pdf/physis/v20n1/a05v20n1.pdf>. http://dx.doi.org/10.1590/S0103-73312010000100005.

. Direito sanitário. Revista Direito e Democracia. Canoas. v. 3, n. 1, p. 7-14, 2002.

; NUNES JÚNIOR, Vidal Serrano. Direito sanitário. São Paulo: Verbatim, 2011.

FIGUEIREDO, Mariana Filchtiner. Direito fundamental à saúde: parâmetros para sua eficácia e efetividade. Porto Alegre: Livr. do Advogado, 2007.

FURTADO, Lucas Rocha. Sistema de propriedade industrial no direito brasileiro. Brasília: Brasília Jurídica, 1996.

HAMMES, Bruno Jorge. O direito de propriedade intelectual. São Leopoldo: Ed. Unisinos, 2002.

HASSIM, Adila; HEYWOOD, Mark; BERGER, Jonathan. Health \& democracy: a guide to human rights, health law and policy in post-apartheid South Africa. South Africa: Siber Ink, 2007.

MAPELLI JÚNIOR, Reynaldo; COIMBRA, Mário; MATOS, Yolanda Alves Pinto Serrano de. Direito sanitário. São Paulo: Imprensa Oficial, 2012.

MUJALLI, Walter Brasil. A propriedade industrial: nova Lei de Patentes. Leme: Ed. de Direito, 1997.

NOBREGA, Ramiro. Acesso a medicamentos: direito garantido no Brasil? In: COSTA, Alexandre Bernardino; SOUSA JÚNIOR, José Geraldo de; DELDUQUE, Maria Célia; OLIVEIRA, Mariana Siqueira de Carvalho; DALLARI, Sueli Gandolfi (Orgs.). O direito achado na rua: introdução crítica ao direito à saúde. Brasília: CEAD/UnB, 2009. p. 307-317.

SALAZAR, Andrea Lazzarini; GROU, Karina Bozola. A defesa da saúde em juízo: teoria e prática. São Paulo: Ed. Verbatim, 2009.

SOARES, José Carlos Tinoco. Tratado da propriedade industrial: patentes e seus sucedâneos. São Paulo: Ed. Jurídica Brasileira, 1998.

TIMM, Luciano Benetti; BRENDLER, Gustavo. Análise econômica da propriedade intelectual: Commons vs. Anticommons. In: CONGRESSO NACIONAL DO CONPEDI, 18., nov. 2009. p. 1017-1037. Anais... Disponível em: <www.conpedi.org.br>. Acesso em: 20 mar. 2015.

Cláudia Karina Ladeia Batista - Doutora em Direito pela Instituição Toledo de Ensino. Professora da Universidade Estadual de Mato Grosso do Sul. Campo Grande/MS, Brasil.

Mário Lúcio Garcez Calil - Doutor em Direito pela Instituição Toledo de Ensino. Professor da Universidade Estadual de Mato Grosso do Sul. Campo Grande/MS, Brasil. E-mail: mario. calil@yahoo.com.br. 